not, then, unreasonable to suppose that there is in the individual a proper amount of the power of repression, and that in some this power is weak and results in hyporepression, while in others it is strong and results in normal repression, or perhaps at times in over or hyperrepression. In hypo-repression that which it has been sought to repress may manifest itself in ways which are recognised by the patient as due to his defective power of repression or in ways which are not so recagnised, and are expressed as symptoms of functional nervous, disease. On the other hand, in hyper-repression in , persons of considerable power of ratiocination and self-control, there may, for a time at least, be periods during which symptoms disappear or are tolerable, but there are likely to be other periods when their powers are weakened, perhaps owing to physical illness or to exhaustion, and when that which is repressed may again emerge and indicate its presence in morbid anxiety, in various symptoms of functional nervous disease, or in the tremendous spiritual conflicts of which accounts are frequent in "Lives of Saints." In this mode of treatment, as in treatment by suggestion, the origin of symptoms has not been investigated.

(3) Analysis.

In one aspect mental analysis is but an elaborated and systematised method of investigating the causes of functional nervous disease, but by its radical methods it also claims to remove the causes of disease and in this way especially to be of therapeutic value. The treatment of symptoms is held, as in general medicine, to be of less value than the discovery and eradication of the causes of disease. These causes are -often of the nature of repressions, which occur in some cases so early that, as it has been observed, it is difficult to determine whether the process is an instinctive one or a result of early education. Repression certainly does occur later in life, when ideas which have been inculcated clash with instincts, or when one set of inculcated ideas clashes with another. In the latter case, at any rate, it is doubtful if it is necessary to carry an examination as far as infancy to discover the repressed idea. But in other cases it would appear that normal psychic growth has not been steadily progressive, and that in some respects it has become stationary, so that a conflict arises between this fixed set of ideas and other sets of ideas which have continued their normal progression.

Some of these fixations and repressions hinge upon the sexual impulse, but it is doubtful if in all cases it is necessary to insist upon such a connexion, at least if the word sexual is to be used in its customary sense. Recently the word has been given an extension which includes the "impulse towards life," relations between parents and children, and ordinary social relations between persons of the same or opposite sex. In the investigation of these relations it is somewhat difficult to avoid the feeling that too great a scope is occasionally allowed to the vagaries of the imagination, for they are extremely difficult to control in scientific investigation. In 'some cases, interpretations, seemingly wild, are confirmed, but occasionally also such interpretations appear to take the nature of a rather dangerous process of suggestion, the process being recognised neither by the patient nor the physician, and an imaginative interpretation is adopted by both and set forth as the canse of the disorder. Further, it is quite obvious to those, having experience of cases which have been systematically investigated that the discovery ensuing from the investigation does not always eventuate in cure, or, even alleviation. Failure to alleviate may be ascribed by the physician to his defective knowledge or faulty art, but when he comes across unrelieved cases which have been treated by the able, experienced, and learned, a similar doubt as to the correct nature of the technique cannot be raised, and he is obliged reluctantly to admit that this method, along with others at present in use, has its limitations.

From the practical point of view the time which a faithful analysis takes, owing to the numerous cross currents, false scents, and mare's-nests, often makes it impracticable as a form of treatment. Whatever the theory as to ætiology adopted, and whatever the mode of treatment practised, it remains true that many, and perhaps the majority, of those suffering from functional nervous disorders get better, and, indeed, happily often lose their symptoms entirely. Many cases have also recovered without any pretence of treatment, or their cure has occurred during a treatment which has not perceptibly been causally connected with it. The repressive forces have perhaps become stronger, or the expanding or centrifugal force of that which is repressed has perhaps become weaker. Inquiry into the nature and strength of such forces is very much needed.

The fruits of experience and thought tend, above all things, to show that psychology is still in its infancy and that morbid psychology is younger still, that we cannot do much therapeutically, but that we can do something, and that we certainly cannot afford in examining a case to leave any stone unturned or in treatment to leave any method untried, whether it be derived from the physical or psychic worlds. To make too hard-and-fast a division between the psychic and the physical is to go unwarrantably beyond the data of experience. As physicians we have to deal with the mind and with the body, and where the sphere of the one begins and the other ends we certainly do not know, nor to what extent, for good or evil, they influence each other.

\section{A CONTRIBUTION TO THE DIAGNOSIS OF}

\section{ACTITE PULMONARY TUBERCULOSIS}

BY JOHN B. MCDOUGALL, M.D. GLASG., M.R.C.P. EdIN., F.R.F.P.S. GLASG.,

CHIEF CLINICAL TUBERCULOSIS OFFICER, WEST RIDING OF YORKSHIRE.

AT the recent Tuberculosis Conference in Leeds it was admitted by the pioneer of auto-inoculation therapy in England, Dr. M. Paterson, that "borderline" cases have been met with occasionally in his own practice. The excellent results at Frimley, however, can only be ascribed to the consummate care with which the patients were selected for graduated exercise, for certain it is that success depends very largely on prolonged rest, graduated if need be, coupled with close clinical observations, in all cases exhibiting signs of active disease in the chest.

This borderline type of patient may be described as follows :-

The temperature is normal when the patient is at rest in bed, and very frequently also on rising to have light exercise in the ward. The pulse-rate fluctuates between 80 and 90 per minute, and may not be more than 95 after dressing. Cough and sputum may or may not be present, and the physical signs in the chest may vary from an apical lesion of small dimensions to extensive disease involving both sides of the chest. The sputum, if present, may show no acid-fast bacilli, or these may be present in small or large numbers. If it be washed and plated, however, it will almost invariably be found to contain secondary invaders in varying numbers and kinds.

Pneumococci and streptococci are common, but staphylococci, Micrococcus catarrhalis, and other organisms are frequently observed. The patient himself has a feeling of comparative well-being, and may complain of nothing except the ennui of restricted freedom. $\mathrm{He}$ is apparently fit and well enough to take a step forward in treatment. The first step may be a successful one, but more frequently it is followed by a rise in temperature, accompanied by the symptoms of uncontrolled auto-inoculation. Much, if not most, of the damage caused by indiscriminate tuberculin therapy has been in this type of case.

Leucocyte Counts giving Quantitative and Qualitative Cell Picture.

With a view to establishing an objective proof of latent activity in this " borderland" type the author" has carried out a large number of blood examinations, the details of which have been published elsewhere. I have found this helpful in guiding to a definite conclusion, one way or another, as to the suitability of a particular case for treatment by graduated rest and exercise.

The method is as follows:-

Total white cell counts are made at intervals during the day; blood examinations during the night are not necessary. 
For practical purposes counts every three hours are sufficient. A note should be made of the temperature and pulserate on each occasion a total white cell count is made. The process should be repeated the following day if possible, and again at later dates until a definite conclusion is arrived at. Blood films are also taken at weekly intervals, the time, date, temperature, and pulse-rate being noted at the same time. A differential white cell count should be made, and finally an Arneth count of the nuclei of the polymorphonuclear leucocytes. A white cell picture is thus obtained. It is quantitative as well as qualitative.

From an analysis of 67 cases in which 150 differential counts of the white cells, together with Arneth counts, were made, and of 30 cases in which 250 total counts were estimated, the following conclusions were reached :-

1. If consecutive daily leucocyte counts are made, a variation in total numbers of white cells is found in all active cases of pulmonary tuberculosis-a variation in excess of that occurring normally in health. (See Leucocyte record A.) 2. Physical signs in the chest may give little or no help in determining the activity of a lesion. For instance, a cavity in the lung may be followed by pathological "repair" and clinical quiescence, and in such a case the total leucocyte count may be small, and the Arneth count but slightly altered. (See B.) Conversely, there may be a definite "leucocyte swing" and a marked "deviation to the left" in cases showing no other objective sign of active disease.

3. The total leucocyte count bears a definite relationship to the acuteness of the lesion in the chest, and the acuteness of the lesion has, in turn, a more or less intimate connexion with the presence of organisms other than the tubercle bacillus.

4. The Arneth "deviation to the left" (a phrase symony mous with an increase in cells of Class I. and II.-i.e., those with one or two nuclear segments) is established in all cases of active disease. The more severe the infection the greater is the deviation to the left. (See C.)

5. An approximation of the quantitative and qualitative blood picture to the normal is a favourable sign and indicates quiescence.

\section{Significance of Total White Cell Count and its} Fluctuations.

Examinations of the sputum and cultures from the lung tissue in all cases of advanced tuberculosis prove that organisms other than the tubercle bacillus play an important part in the bacteriology of the disease (Ortner, ${ }^{1}$ Petroff, ${ }^{2}$ Ravenel and Irwin, ${ }^{3}$ and others.) We know that, unlike the pneumococcus, ${ }^{4}$ the toxins of the tubercle bacillus do not stimulate the production of polymorphonuclear cells. It is the rule to find leucopenia with relative lymphocytosis in early and also in advanced but quiescent cases of phthisis. Further clinical proof of the fact that the tubercle toxins do not encourage leucocytosis may be cited from the blood investigations in cases of miliary tuberculosis, where massive doses of tubercle toxin are constantly in the circulation. (See D, from Cabot.) All authorities agree that leucopenia is the rule in these cases. From two cases seen I am in a position to verify this statement. Treadgold's animal experiments are significant. ${ }^{\tilde{}}$

It would appear, therefore, that the leucocytosis found in cases of active pulmonary tuberculosis is an indication of the "septic" element in the pathology of the disease, and it may be deduced that these "secondary" invaders give rise to hæmatological changes in the absence of other clinical signs of active disease in the lung.

To explain the low counts which interpolate themselves with such regularity and frequency in certain cases of pulmonary tuberculosis is difficult. They are not due to rest, nor can bone-marrow exhaustion explain them. Bone-marrow exhaustion, however, is not to be diagnosed from estimations of the total leucocyte count alone. The qualitative picture must also be considered. An apparently satisfactory quantitative reaction may be in reality a bad qualitative one, indicating failure of the bone-marrow. A third possible explanation of the "leucocyte swing" is that it is due to periodical intermissions from the diseased focus of substances acting on the polymorphonuclear cells by negative chemiotaxis. 6 The balance between the various toxins can never be equal, and in this way the leucocyte swing is maintained, being elevated when the "pyogenic" toxins are in excess, and being low when the blood stream is surcharged with tubercle toxin.
Significance of " Deviation to the Left" (Arneth).

The precise significance of the "deviation to the left" in the presence of an infection is problematical. This was dealt with in a note on "The Neutrophile Index" in THE LANCET of April 24th, 1920. I regard the excess of cells with one or two-lobed nuclei as due to an increased and excessive demand on the activities of the bone marrow. It is unfair to assume that the bone marrow can keep up a satisfactory response in quantity and quality over a long period of time, as in mixed pulmonary infection. Quality suffers before quantity, if we are to take the Arneth deviation to the left as a criterion of cellular efficiency; and from the large mass of work which has been done on the Arneth count, we are entitled to believe that the cells in Classes I. and Ir. are indicative of an ebbing immunity when they re in excess.

In the presence of a large number of "single-lobed", polymorphs such as is found in acute infection it is matter for surprise that myelocytes are not found much more frequently. Cells described as myelocytes have been found by Wack and Kast, ${ }^{8}$ working independently. Personally $I$ have never been able to identify true myelocytes in any of the films I have examined, not even in cases where the index has been over 95. It may be said, I think, that the deviation to the left is an expression of qualitative bone-marrow exhaustion, as distinct from quantitative. In miliary tuberculosis it has been shown that a leucocytosis is not a feature of the disease, and yet the Arneth count exhibits a deviation to the left as in most intoxications. (See E.) So also in intestinal diseases in children, it has been pointed out by Esser ${ }^{9}$ that a similar phenomenon may be observed. I know of no observations which have been made on the neutrophile index in patients suffering from syphilis, whooping-cough, or typhoid fever, but until further observations are forthcoming in these diseases it can be suggested tentatively that aggressins, or the toxins associated with organisms which do not cause leucoplastic reaction, act on the bone marrow by inhibiting the development of the young polymorphic cell.

Some Illustrative Lencocyte Records.

A. On admission patient was pale and very much emaciated. At first the temperature was very unsteady, running between $98^{\circ}$ and $100^{\circ} \mathrm{F}$. The pulse-rate did not come below 90 per minute, despite evening temperature on Jan. 24 th being normal. Several examinations of the sputum were made; on each occasion tubercle bacilli

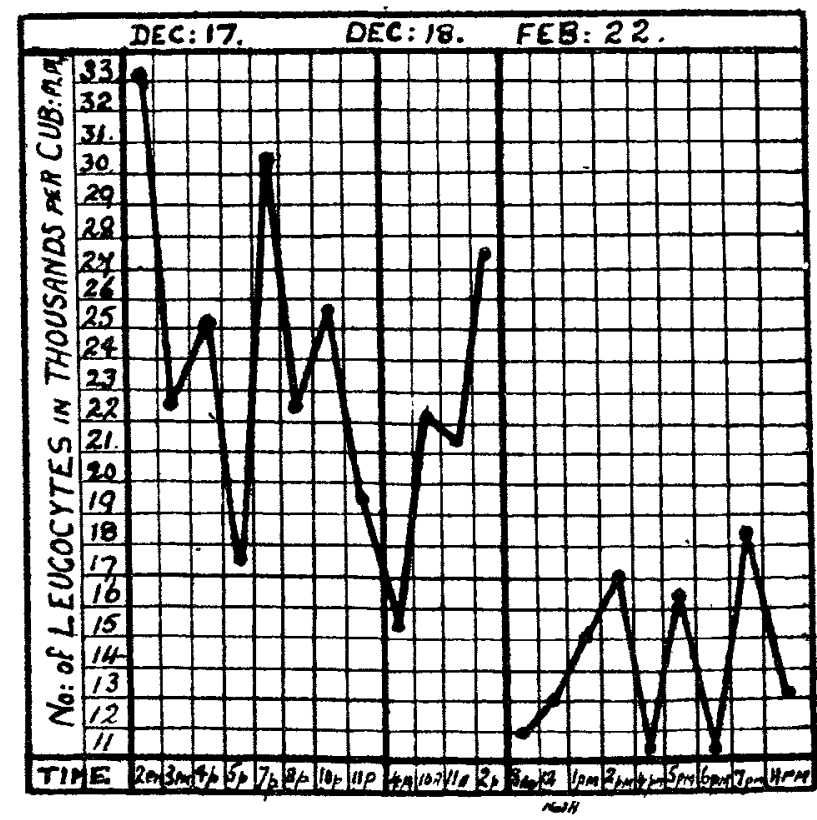

Fig. 1.- Leucocyte counts were made on Dec.17th at 2, 3, 4, 5, 7 , 8,10 , and 11 P.M. ; on Dec. 18th at 4, 10,11 A.M. and 2 P.M.; on Feb. 22nd at 8 A.M., noon, 1, 2, 4, 5, 6, 7, and 11 P.M.

were found. The physical signs in the chest showed impairment of resonance over right upper lobe with harsh breath sounds and numerous crepitations over the same area. On Feb. 29 th the case closed dramatically. Hæmoptysis was so profuse that patient died five minutes after onset of bleeding. (Fig. 1.)

B. Patient was extremely emaciated. T. $99^{\circ} 4^{\circ}-100^{\circ} 4^{\circ} \mathrm{F}$. The sputum contained tubercle bacilli in large numbers -50 to 60 to the field. 
Both sides of the chest, back and front, were dull to percussion 'On auscultation, the respiratory murmur was very harsh over the entire chest. especially on left side, where whispering pectoriloquy could be heard. There were other definite signs of cavity formation over the upper lobe on left side. Numerous moist sounds accompanied both inspiration and expiration in both upper lobes. Arneth index, 71 ' 5 . (Fig. 2.)

C. Male, aged 24, Onset three months previous to date of first blood examination. Family history bad General condition poor. Temperature $99^{\circ}$ to $102^{\circ} \mathrm{F}$ Pulse 100 to 110 per minute. Signs of acute disease in left lung and in upper lobe of right lung. Sputum contained tubercle baeilli,
streptococei, staphylococci, and numerous diplococei Patient died Dec. 24th.

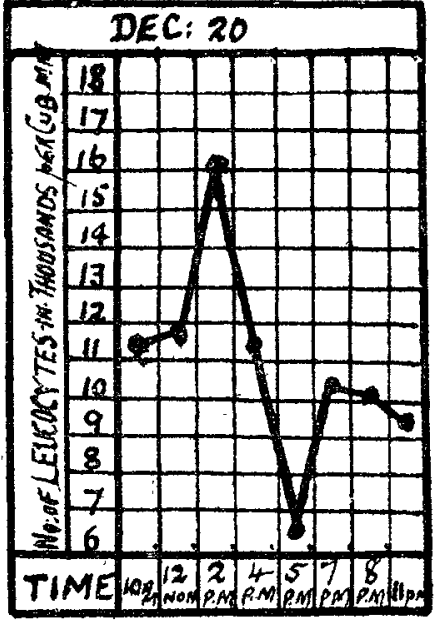

Class...

$\begin{array}{ccccc}\text { I. } & & \text { II. } & & \text { II } \\ 42 & \ldots & 46 & \ldots & 12 \\ 47 & \ldots & 45 & \ldots & 8 \\ 48 & \ldots & 45 & \ldots & 7\end{array}$

III.
12
8
7 Fia. 2.- Lencocyte counts were
made at 10 A.M., noon, $2,4,5,7$, 8, and 11 P.M.

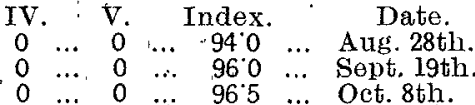

D. (From Cabot.)-Miliary Tuberculosis.

Date. Time. Leucocytes! Date. Time. Lencocytes

perc.mm. Date.

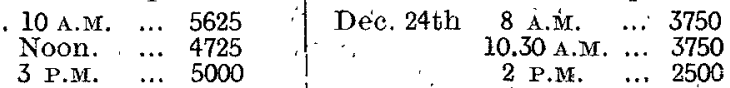

5 P.M. $\cdots 3125$

2 P.M. $\quad \cdots \quad 2500$

E. Arneth Count from a Case of Miliary Tuberculosis.

Class ... I. . II. , III. IV. Index.

References.-1. Ortner: THE IANOET, clxxxii., 876, quoted by Inman. 2. Petroff: L'Infection Mixte dans la Tuberculose Chiruxgicale, Annales de l'Institut Pasteur, 1904, xviii., 502. 3. Ravenel and Irwin: Studies in Mixed Infection in Tubereulosis, Trans. Nat. Assoc. for Study and Prevention of Tuberculosis, Lancaster, Pa. U.S.A. New Era Printing Company, 1905 4. Gulland and Gooda11. The.Blood: A Guide to its Examination and to the Diagnosi and Treatment of its Diseases, W. Green and Son, 1914, p. 315 . and Treatment of its Diseases, W. Green and Son, 1914, p. 315 5. H. A. Treadgold: THE LANCET, 1920, i., 699. 6. Bail : Berlin
klin. Woch. 1905, 15, and other papers. 7. Sauerbeck: Zeit. f. Hyg., klin. Wock., 1905, 15, and other papers. 7. Sauerbeck: Zeit. f. Hyg., 1vi, 1907. 8. P. Wack: Deutsches Archiv fürklinische Medicin, 19

\section{BILHARZIA TREATED WITH TARTAR EMETIC:}

BY F. G. CAWSTON, M.D. CANTAB.

THE study of a number of bilharzia patients who have undergone a course of treatment by intravenous injections of tartar emetic would appear to show that the best results are obtained where the injections are given on alternate days for most of the time, and the treatment is continued for a complete month. It has been my practice to commence with gr. $\frac{1}{4}$, and in only one case of idiosyncrasy have I noticed any severe effect from this initial dose. On that occasion the patient of 15 experienced great abdominal pain, vomiting, and collapse about four hours after the administration of the drug; this condition lasted till midnight. The second day I give half a grain, and on the third threequarters. I then give, on alternate days, from one to one-and-a-half grains, and continue the injections for three to five weeks, according to the disappearance of ova from the urine. If the solution is absolutely fresh and the injections are given regularly, a total of from 12 to $15 \mathrm{gr}$. would seem to be sufficient to effect a permanent cure in the majority of cases.

Toxic effects are less common in patients who are given a solution of the drug which has not been freshly prepared, and it is reasonable to suppose that the drug loses much of its effectiveness if the solution is allowed to stand for even a short while after it has been made and boiled. There is also the danger of fungus-growth in solutions of tartar emetic. This presents the appearance of small flakes of cotton-wool, and is noticeable after the solution has been standing for only a few hours. The risk of injecting even small quantities of this into the general circulation can be avoided by dissolving the powdered tartar emetic by boilin' in distilled water and injecting it before it has become cold. I find a solution of $\mathrm{gr} .4$ in $16 \mathrm{c.cm}$. of distilled water is a suitable preparation to give in all cases that have come under my care. This renders an ordinary hypodermic syringe a convenient one to use for the smaller doses.

There is an accumulative effect of tartar emetic which was well shown in a patient of mine whose skin under a wrist-watch was markedky blackened after receiving a total of $12 \mathrm{gr}$. of the drug. By giving the injections on alternate days we make good use of this accumulative action and make smaller doses more effective. As a rule, dally injections should be avoided, for the patient should be given time to recover from all toxic effects of the drug before receiving further injections. Toxic effects are undoubtedly lessened where the injections are given shortly after a light breakfast, instear of later on in the day. This point has been emphasised by Dr. J. B. Christopherson, ${ }^{1}$ and is borne out by my own experience.

In the series of cases given in Table I. a comparatively small total dosage has proved sufficient, for in every instance the ova degenerated gradually until they dis. appeared completely, and the urine has remained free from blood for periods of from two to six months.

TABLE I.

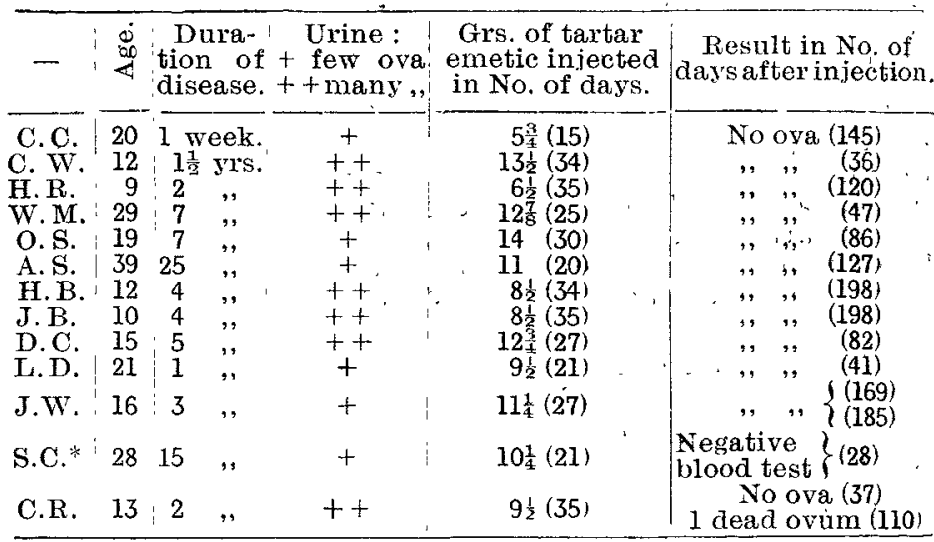

With positive blood test

In the series of cases given in Table II. where the attendance of the patients was irregular or the course of injections stopped early for one cause or another, degenerated ova were found in the specimens of urine

\begin{tabular}{|c|c|c|c|c|c|}
\hline- & $\dot{S}_{4}^{0}$ & 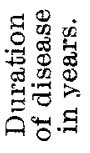 & 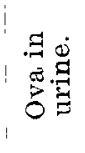 & $\begin{array}{l}\text { Grs. of tartar } \\
\text { enetic in- } \\
\text { jected in No. } \\
\text { of days. }\end{array}$ & $\begin{array}{r}\text { : } \\
\text { Remarks. } \\
\text { - }\end{array}$ \\
\hline E. T. & $\mathrm{I} 6$ & $5 \frac{1}{2}$ & ++ & $13 \frac{1}{2}(25)$ & $\begin{array}{l}\text { Hæmaturia after } 108 \text { days. } \\
\text { (Ova all apparently dead.) }\end{array}$ \\
\hline H. W: & 24 & $5 \frac{1}{3}$ & $+t$ & $12 \frac{1}{2}(24)$ & $\begin{array}{c}\text { Two ova, one alive after } \\
92 \text { days. }\end{array}$ \\
\hline J. C. & 21 & $1 \frac{1}{3}$ & ++ & $10 \frac{1}{s}(21)$ & Hrematuria after 177 days. \\
\hline F. G. & 16 & 4 & ++ & $11(38):$ & $\begin{array}{c}\text { Many ova after } 76 \text { days. } \\
\text { (Degenerated.) }\end{array}$ \\
\hline B. $\mathbf{T}$. & 17 & 7 & ++ & $12^{2}(25) !$ & Living ova after 62 days. \\
\hline F. MeN. & 15 & 5 & + & $12 \frac{1}{4}(32) !$ & Living ova after 73 days. \\
\hline
\end{tabular}
examined some weeks after the injections ceased.

TABLE' II.

* Missed three days running. I Missed four days.

Two apparently dead ova were found in another patient's urine 277 days after treatment had ceased He had received a total of $12 \frac{3}{4} \mathrm{gr}$. in 40 days, besides some intramuscular injections of collosol antimonium As he had suffered from hæmaturia daily for the previous 18 years and had seen no suggestion of it since his treatment, it is reasonable to suppose that he is cured of the disease. Another, whose treatment was discontinued at the end of only a fortnight on account of a severe "cold" following an injection in January last, reported a recurrence of his symptoms three months later. He had received a total of under $9 \mathrm{gr}$. of tartar emetic, and a full course of $15 \mathrm{gr}$. was given to make his cure complete.

Durban.

1 Journal of Trop. Med. and Hyg., July 15th, 1919. 